Compromised Peak Bone Mass in Patients with Inflammatory Bowel Disease-A Prospective Study

\title{
Laakso, Saila
}

2014-06

Laakso, S , Valta , H , Verkasalo , M , Toiviainen-Salo, S \& Makitie , O 2014 , '

Compromised Peak Bone Mass in Patients with Inflammatory Bowel Disease-A Prospective

Study ' , The Journal of Pediatrics , vol. 164 , no. 6 , pp. 1436-+ . https://doi.org/10.1016/j.jpeds.2014.01.073

http://hdl.handle.net/10138/291914

https://doi.org/10.1016/j.jpeds.2014.01.073

publishedVersion

Downloaded from Helda, University of Helsinki institutional repository.

This is an electronic reprint of the original article.

This reprint may differ from the original in pagination and typographic detail.

Please cite the original version. 


\title{
Compromised Peak Bone Mass in Patients with Inflammatory Bowel Disease-A Prospective Study
}

\author{
Saila Laakso, $\mathrm{MD}, \mathrm{PhD}^{1}$, Helena Valta, $\mathrm{MD}, \mathrm{PhD}^{1}$, Matti Verkasalo, $\mathrm{MD}, \mathrm{PhD}^{1}$, Sanna Toiviainen-Salo, MD, $\mathrm{PhD}^{2}$, \\ and Outi Mäkitie, MD, $\mathrm{PhD}^{1,3,4}$
}

Objective To evaluate peak bone mass attainment in children and adolescents with inflammatory bowel disease and to identify risk factors for suboptimal bone mass attainment.

Study design We conducted a prospective follow-up study of 47 children and adolescents (24 males) with ulcerative colitis $(n=30)$ or Crohn's disease $(n=17)$. They were assessed for lumbar spine areal bone mineral density (aBMD) and for height-adjusted whole body less head bone mineral content (BMC); the values were corrected for bone age.

Results Altogether, $73 \%$ of the patients had completed pubertal development after the median follow-up time of over 5 years. Despite clinical inactivity of the disease in $70 \%$ of the patients at the follow-up visit, BMD or BMC Z-scores improved in none of the measurement sites. Lumbar spine aBMD Z-scores (mean difference [95\% Cl], -0.47 [-0.92 to -0.03 ]; $P=.04$ ) and whole body less head BMC height- and bone age-adjusted Z-scores $(-0.52$ [ -1.01 to -0.02 ]; $P=.04)$ decreased in patients who were pubertal at baseline and completed their pubertal development during the follow-up. Postpubertal patients had lower aBMD and BMC Z-scores in comparison with prepubertal and pubertal patients. Low lumbar spine aBMD (Z-score < -1.0) was associated with completed pubertal development, underweight, and greater lifetime cumulative weight-adjusted prednisolone dose. Vertebral fractures were detected in 3 patients $(6 \%)$. One-fourth of the patients had insufficient serum 25-hydroxyvitamin D concentrations (<50 nmol/L).

Conclusions The longitudinal follow-up over the pubertal years shows that inflammatory bowel disease poses a significant threat for bone health. The suboptimal peak bone mass attainment may have life-long consequences. $(J$ Pediatr 2014;164:1436-43).

nflammatory bowel disease (IBD) is a risk for normal growth and pubertal development; inflammation, malnutrition, and glucocorticoid (GC) treatment contribute to these and to impaired bone health. ${ }^{1-4}$ Longitudinal studies indicate that bone mass accrual is subnormal. ${ }^{5-7}$ Premenopausal women with Crohn's disease (CD) with disease onset before age 16 years demonstrated significantly reduced areal bone mineral density (aBMD). ${ }^{8}$ Two longitudinal studies with peripheral quantitative computed tomography (pQCT) showed in pediatric patients with $\mathrm{CD}$ or ulcerative colitis (UC), incomplete improvements in muscle mass, trabecular volumetric bone mineral density (vBMD), and bone geometry after median 1 and 2.6 years' follow-up. ${ }^{9,10}$ The 1-year prospective study from diagnosis demonstrated greater increases in vBMD in prepubertal and early pubertal subjects with CD compared with more mature subjects. ${ }^{9}$. Followup times in previous studies have been short and bone health in young adults with childhood onset IBD thus remains unknown.

We conducted a prospective follow-up study of more than 5 years in children and adolescents with IBD. Most of the patients completed pubertal development during the follow-up. Disease characteristics, treatments, growth, and pubertal development were correlated with bone mass measurements to identify risk factors for low BMD.

\begin{tabular}{|c|c|c|c|}
\hline $\begin{array}{l}25(\mathrm{OH}) \mathrm{D} \\
\mathrm{aBMD}\end{array}$ & $\begin{array}{l}25-\text { Hydroxyvitamin } \mathrm{D} \\
\text { Areal bone mineral density }\end{array}$ & PCDAI & $\begin{array}{l}\text { Pediatric Crohn's Disease Activity } \\
\text { Index }\end{array}$ \\
\hline BA & Bone age & PQCT & Peripheral quantitative computed \\
\hline BMC & Bone mineral content & & tomography \\
\hline $\mathrm{Ca}$ & Calcium & P-PTH & Plasma parathyroid hormone \\
\hline CD & Crohn's disease & PUCAI & Pediatric Ulcerative Colitis Activity \\
\hline DXA & Dual-energy X-ray absorptiometry & & Index \\
\hline FM & Fat mass & SCCAI & Simple Clinical Colitis Activity \\
\hline GC & Glucocorticoid & & Index \\
\hline $\mathrm{HBI}$ & Harvey-Bradshaw Index & UC & Ulcerative colitis \\
\hline IBD & Inflammatory bowel disease & vBMD & Volumetric bone mineral density \\
\hline \multirow[t]{2}{*}{ LM } & Lean mass & VF & Vertebral fracture \\
\hline & & VFA & Vertebral fracture assessment \\
\hline
\end{tabular}

From the ${ }^{1}$ Children's Hospital, Helsinki University Central Hospital and University of Helsinki; ${ }^{2}$ Helsinki Medical Imaging Center, Department of Pediatric Radiology, Helsinki University Central Hospital; ${ }^{3}$ Folkhälsan Research Center, Biomedicum Helsinki, Helsinki, Finland; and ${ }^{4}$ Department of Molecular Medicine and Surgery, Karolinska Institutet, Stockholm, Sweden

Supported by the Sigrid Juselius Foundation, the Finnish Medical Foundation, the Finnish Foundation for Pediatric Research, the Academy of Finland, the Folkhälsan Research Foundation, and the Helsinki University Hospital Research Funds. The authors declare no conflicts of interest.

0022-3476/\$ - see front matter. Copyright @ 2014 Elsevier Inc. All rights reserved.

http://dx.doi.org/10.1016/j.jpeds.2014.01.073 
mean height for age and sex. ${ }^{21,22}$ Patients $<18$ years were regarded underweight, normal weight, or overweight according to Finnish pediatric body mass index references. ${ }^{23}$ Adults This prospective cohort study involved 47 (24 males) children, adolescents, and young adults with IBD, diagnosed according to the Lennard-Jones criteria. ${ }^{11}$ Altogether, 80 (43 females) patients participated in baseline assessment between June 2004 and December $2005^{12}$ and 47 (59\%) of them in the follow-up examination between May 2010 and December 2010. Participants and nonparticipants did not differ in age, pubertal state, diagnosis, disease duration or activity, aBMD Z-scores, frequency of delayed bone age (BA), or cumulative prednisolone dose for the previous 3 years. At baseline, all patients were treated at the Outpatient Clinic for Pediatric Gastroenterology at the Children's Hospital, Helsinki University Central Hospital. The inclusion criteria were age between 4 and 20 years and IBD diagnosed at least 3 months before enrollment. Subjects were ineligible if they had other medical conditions unrelated to IBD that could affect growth or bone mass accrual. The study protocol was approved by the institutional research ethics committee. A written informed consent was obtained from all participants and/or their guardians.

Medical records were reviewed for disease and treatment characteristics. Disease duration was calculated from the date of the first diagnostic gastroenterological endoscopy. Lifetime weight-adjusted (dose per body weight) cumulative exposure of orally and parenterally administered prednisolone equivalents was calculated. Fracture history, including localization and trauma mechanism, were recorded. Fractures resulting from falls from standing height or less were regarded low-energy fractures. A 3-day dietary recall was obtained for $33(70 \%)$ patients; they were analyzed using the Finnish National Food Composition Database (Fineli; National Institute of Health and Welfare, Helsinki, Finland), and dietary and total (including supplements) intakes of calcium $(\mathrm{Ca})$ and vitamin $\mathrm{D}$ were calculated.

Patients were clinically assessed; imaging studies and laboratory measurements were performed at the same visit. Pubertal status was determined according to Tanner staging. ${ }^{13}$ Age at menarche was determined by interview. Disease activity was scored in CD with Pediatric Crohn's Disease Activity Index (PCDAI) before age 20 years ${ }^{14}$ and Harvey-Bradshaw Index (HBI) in adults, ${ }^{15}$ and in UC with Pediatric Ulcerative Colitis Activity Index (PUCAI) in adolescents ${ }^{16}$ and Simple Clinical Colitis Activity Index (SCCAI) in adults. ${ }^{17}$ The patients were classified as having: (1) "moderate/severe disease" at examination, if $\mathrm{PCDAI}$ was $\geq 30$, HBI $\geq 8$, PUCAI $\geq 35$, or SCCAI $\geq 5$; (2) "mild disease" if PCDAI $\geq 10$ and $<30, \mathrm{HBI} \geq 5$ and $<8$, PUCAI $\geq 10$ and $<35$, or SCCAI $>2$ and $<5$; or (3) "inactive disease" if PCDAI $<10$, HBI $<5$, PUCAI $<10$, or SCCAI $\leq 2$. $^{14,16,18-20}$

\section{Growth Assessment}

Height was measured with a Harpenden stadiometer (Holtain Limited, Crymych, United Kingdom) and weight in thin underwear with an electric scale. Height Z-score was defined as a deviation of height, in SD scores, from the were classified underweight, normal weight, or overweight by body mass index $<18.5 \mathrm{~kg} / \mathrm{m}^{2}, 18.5-25 \mathrm{~kg} / \mathrm{m}^{2}$, or $>25 \mathrm{~kg} / \mathrm{m}^{2}$, respectively. ${ }^{24}$ Parental heights were obtained from medical records and parent-specific expected height SD scores were calculated. ${ }^{25,26}$

\section{Imaging Studies}

BA was determined for prepubertal and pubertal patients $(n=17)$ from a left hand radiograph ${ }^{27}$ and considered delayed or advanced when it differed from calendar age more than 1 year; BA-adjusted BMD, bone mineral content (BMC), and height values were used in these cases. aBMD $\left(\mathrm{g} / \mathrm{cm}^{2}\right)$, BMC $(\mathrm{g})$, lean mass (LM), and fat mass (FM) were measured at both time points with dual-energy X-ray absorptiometry (DXA; pediatric software, Discovery A, version 12.4; Hologic, Bedford, Massachusetts). Calibration of the measurements was performed by using a spine phantom; inter-assay coefficient of variation for the phantom BMC, area, and $\mathrm{BMD}$ were $0.35 \%, 0.21 \%$, and $0.41 \%$, respectively. Lumbar spine (L1-L4) aBMD values were transformed into Z-scores by comparing with age- and sex-adjusted reference data for white subjects in the US. We calculated height-adjusted Z-scores for whole body less head BMC values using the least mean square algorithm with age- and sex-adjusted reference data for nonblack subjects for ages 5-20 years. ${ }^{28} \mathrm{Z}$-scores for LM for height (age $<20$ years), ratio of $\mathrm{LM}$ to height ${ }^{2}$ (age $\geq 20$ years), percent FM for age (age $<20$ years), and ratio of FM to height ${ }^{2}$ (age $\geq 20$ years) were calculated using the least mean square algorithm. ${ }^{29}$

Spinal compression fractures were determined from lateral spinal radiographs and from DXA-derived vertebral fracture assessment (VFA) images. Vertebral fractures (VF) were graded as mild (Grade 2a; 20\%-49\% anterior height reduction) or severe ( $2 \mathrm{~b} ; \geq 50 \%$ anterior height reduction) wedge deformities, or mild (3a; vertebral middle and/or posterior height reduction $20 \%-29 \%$ ) or severe (3b; vertebral middle and/or posterior height reduction $\geq 30 \%$ ) compression deformities. ${ }^{30}$ The VFA and radiograph images were assessed independently by two experienced readers; discrepancies were reviewed for consensus.

\section{Biochemistry}

Blood count and erythrocyte sedimentation rate, plasma $\mathrm{Ca}$, phosphate, alkaline phosphatase and albumin, and serum testosterone, estradiol, and dehydroepiandrosteronesulfate were measured by standard methods. Serum 25-hydroxyvitamin $\mathrm{D}[25(\mathrm{OH}) \mathrm{D}]$ was assessed by liquid chromatography; the laboratory's reference range was $>40 \mathrm{nmol} / \mathrm{L}$ and target level in children $50-150 \mathrm{nmol} / \mathrm{L}$, and plasma fasting parathyroid hormone (P-PTH) by an immunometric assay (IMMULITE 2000; Diagnostic Products, Los Angeles, California); the reference range was 8-73 $\mathrm{ng} / \mathrm{L}$. Urine was analyzed for $\mathrm{Ca} /$ creatinine. 


\section{Statistical Analyses}

The differences in categorical variables were tested with Pearson $\chi^{2}$ test or 2-sample test for equality of proportions with continuity correction. A $t$ test was used when we compared characteristics between 2 groups of patients. For nonnormally distributed parameters, we used the MannWhitney nonparametric $U$ test. One-sample $t$ test was used to test whether mean aBMD and BMC Z-scores differed significantly from zero. The strength of relationship between delta height SDS or cumulative weight-adjusted prednisolone dose during follow-up and delta lumbar spine BMD or whole body less head BMC Z-scores was estimated using Kendall rank correlation. The differences in parameters between the 2 examinations were tested with paired samples $t$ test. $P<.05$ was considered statistically significant. All statistical analyses were performed with IBM SPSS 20.0.0 statistical package for Mac (SPSS Inc, Chicago, Illinois) except 2-sample tests for equality of proportions with continuity correction that were performed with $\mathrm{R}$ statistical program, version 2.15.2 (www.r-project.org/).

\section{Results}

Altogether 47 patients (24 males) were prospectively followed from median age of 14.5 years to this follow-up assessment at the median age of 19.7 years; 30 patients (64\%) had UC, and 17 (36\%) had CD (Table I). At the follow-up visit, mean disease duration was 8.6 years, the majority $(>70 \%)$ had inactive disease, and 11 (23\%) used no daily oral medication for IBD.

\section{Pubertal State, Anthropometrics, and Bone Measurements at Follow-Up Assessment}

At the time of diagnosis, 25 of the patients were prepubertal, 20 pubertal, and two postpubertal. At follow-up, the majority (75\%) had completed pubertal development. Six (13\%) subjects had delayed BA (4 boys). Median age at menarche in postpubertal girls $(\mathrm{n}=19)$ was 14 years (range, 12-20 years). The patient with latest menarche had otherwise-normal pubertal development but primary amenorrhea. In one boy, puberty was induced with testosterone in 6 months. Serum testosterone and estradiol levels were appropriate for pubertal state, whereas 2 postpubertal boys had preadrenarcheal serum dehydroepiandrosteronesulfate levels $(<1.0 \mu \mathrm{M})$.

On average the BA-adjusted height SDS (median [range], $0[-2.8$ to 3.1]) did not differ significantly from the calculated target height SDS (0.2 [ -0.9 to 1.9], $P=.88)$. Five (14\%) of the postpubertal subjects were underweight, $25(71 \%)$ normal weight, and $5(14 \%)$ overweight. None of the prepubertal or pubertal subjects were underweight, and $4(33 \%)$ were overweight. aBMD BA-adjusted Z-scores for lumbar spine and BMC height- and BA-adjusted Z-scores for whole body less head were significantly below the expected mean value (Zscore 0 ), and lower in postpubertal patients in comparison with the group of prepubertal and pubertal patients (Table II). P-PTH was supranormal $(>73 \mathrm{ng} / \mathrm{L})$ in 3 patients. Four patients had hypercalciuria (urine $\mathrm{Ca} /$ creatinine $\geq 0.7$ ); none had hypocalcemia. Hypophosphatemia (P-phosphate
Table I. Characteristics of the 47 patients with IBD

\begin{tabular}{|c|c|}
\hline Characteristic & n (\%) or median (range) \\
\hline Diagnosis (UC/CD) & $30(64 \%) / 17(36 \%)$ \\
\hline Sex (boy/girl) & $24(51 \%) / 23(49 \%)$ \\
\hline Age at baseline, y & $14.5(5.1-19.2)$ \\
\hline Age at examination, $y$ & $19.7(10.7-25.0)$ \\
\hline Patients older than $20 \mathrm{y}$ & $23(49 \%)$ \\
\hline Follow-up time, y & $5.4(4.9-6.3)$ \\
\hline Age at diagnosis, y & $10.2(2.1-15.3)$ \\
\hline Duration of disease, $y$ & $8.6(6.0-19.8)$ \\
\hline $\begin{array}{l}\text { Disease activity at study visit } \\
\text { (inactive/mild/moderate-severe) }\end{array}$ & $34(72 \%) / 11(23 \%) / 2(4 \%)$ \\
\hline Surgery during follow-up (IBD-related) & $8(17 \%)$ \\
\hline Colectomy during lifetime & $7(15 \%)$ \\
\hline \multicolumn{2}{|l|}{ Medication } \\
\hline 5-ASA (lifetime/current) & $47(100 \%) / 26(55 \%)$ \\
\hline Sulfasalazine (lifetime/current) & $7(15 \%) / 4(9 \%)$ \\
\hline Azathioprine (lifetime/current) & $26(55 \%) / 11(23 \%)$ \\
\hline Infliximab (lifetime/current) & $9(19 \%) / 3(6 \%)$ \\
\hline Adalimumab (lifetime/current) & $7(15 \%) / 5(11 \%)$ \\
\hline Oral GCs (lifetime/current) & $43(91 \%) / 7(15 \%)$ \\
\hline $\begin{array}{l}\text { No current use of daily oral } \\
\text { IBD medication }\end{array}$ & $11(23 \%)$ \\
\hline $\begin{array}{l}\text { Lifetime cumulative weight-adjusted } \\
\text { prednisolone dose, } \mathrm{mg} / \mathrm{kg} \mathrm{n}=44\end{array}$ & $160(1.8-1320)$ \\
\hline $\begin{array}{l}\text { Lifetime duration of GC treatment, } \mathrm{d} \text {, } \\
\quad \mathrm{n}=44\end{array}$ & $507(21-4110)$ \\
\hline $\begin{array}{l}\text { Cumulative weight-adjusted prednisolone } \\
\text { dose during follow-up time, } \mathrm{mg} / \mathrm{kg}, \mathrm{n}=29\end{array}$ & $82(2.1-930)$ \\
\hline $\begin{array}{l}\text { Duration of GC treatment during follow-up time, } \\
\qquad \mathrm{d}, \mathrm{n}=29\end{array}$ & $349(8-2093)$ \\
\hline \multicolumn{2}{|l|}{ Biochemistry } \\
\hline $\mathrm{ESR}, \mathrm{mm} / \mathrm{h}$ & $5(2-30)$ \\
\hline Hemoglobin, g/L & $134(103-171)$ \\
\hline HCT, \% & $40(31-49)$ \\
\hline Plasma albumin, $g / L$ & $39(31-53)$ \\
\hline
\end{tabular}

5-ASA, 5-aminosalicylid acid; ESR, erythrocyte sedimentation rate; $H C T$, hematocrit.

$<0.8 \mathrm{mM}$ ) was measured in 3 patients. Plasma alkaline phosphatase was above the age- and sex-specific reference values in 5 patients. One of the patients with abnormalities in laboratory tests had tubulointerstitial nephritis and secondary hyperparathyroidism (P-PTH 239 ng/L), and others had no metabolic bone disease unrelated to IBD.

Low lumbar spine BA-adjusted aBMD $(<-1.0 \mathrm{Z}$-score $)$ was observed in $17(36 \%)$ patients. Patients with low lumbar spine aBMD were all postpubertal, more often underweight, and had lower height SDS and LM Z-scores than those with greater aBMD (Table III). Lifetime cumulative weightadjusted prednisolone dose was significantly greater and cumulative duration of GC treatment longer among patients with low aBMD. When we restricted analysis to postpubertal subjects, low lumbar spine BA-adjusted aBMD was associated with greater cumulative weightadjusted prednisolone dose $(P=.002)$, longer lifetime duration of GC treatment $(P=.02)$, underweight $(P=.03)$, lower height $(P=.008)$, and LM Z-scores $(P=.006)$.

\section{Bone Mass Accrual, Growth, and Vitamin D Status over Follow-Up Time}

No improvement in bone mineral accrual rate was found in any site of measurement during follow-up (Figure). In the 
Table II. aBMD and BMC Z-scores, and body composition in patients with pediatric onset of IBD altogether and according to pubertal states

\begin{tabular}{|c|c|c|c|c|c|}
\hline Characteristic median (range) & All & $P$ value $^{\star}$ & Prepubertal and pubertal, $n=12$ & Postpubertal, $n=33$ & $P$ value $^{\dagger}$ \\
\hline Lumbar spine aBMD BA Z-score & $-0.7(-3.3$ to 3.3$)$ & $<.001$ & -0.5 (-1.0 to 3.3$)$ & $-1.1(-3.3$ to 0.7$)$ & .005 \\
\hline Whole body less head BMC HAZ-score & $-0.1(-2.9$ to 2.0$)$ & .04 & $0.3(-0.6$ to 1.0$)$ & $-0.3(-2.9$ to 2.0$)$ & .04 \\
\hline LM Z-score & $-0.5(-2.6$ to 1.2$)$ & $<.001$ & $-0.8(-2.5$ to 0.6$)$ & $-0.4(-2.6$ to 1.2$)$ & .45 \\
\hline FM Z-score & $-0.9(-4.5$ to 1.5$)$ & $<.001$ & $-0.6(-4.5$ to 1.4$)$ & $-1.0(-2.8$ to 0.8$)$ & .39 \\
\hline
\end{tabular}

$H A Z$, height- and BA-adjusted Z-score.

${ }^{\star} P$ values from one-sample $t$ test.

$\dagger P$ values from independent samples $t$ test comparing the group of prepubertal and pubertal patients to the group of postpubertal patients

whole group, whole body less head BMC height- and BA-adjusted Z-scores decreased significantly (mean difference $[95 \% \mathrm{CI}],-0.31[-0.54$ to -0.09$]$; Figure). In patients treated with tumor necrosis factor- $\alpha$ antibodies at follow-up assessment $(\mathrm{n}=8)$, the corresponding change in Z-scores was on average -0.20 ( -0.73 to 0.33 , $P=.37)$. Altogether, 23 patients had inactive disease at both baseline and follow-up assessments. Their whole body less head BMC BA-and height-adjusted Z-scores also decreased during follow-up $(-0.5[-0.9$ to -0.2$]$, $P=.006)$. Cumulative weight-adjusted prednisolone dose, reflecting disease activity during the follow-up, did not correlate with the changes in lumbar spine aBMD BAadjusted Z-scores $(\tau=-0.04, P=.78)$ or whole body less head BMC BA-and height-adjusted Z-scores $(\tau=-0.07, P=.64)$. To estimate the bone mineral accrual according to pubertal development, BA-adjusted aBMD and BMC Z-scores at the 2 time points were plotted on the basis of the pubertal state at first examination (Figure). There was no improvement seen during follow-up time in the BA-adjusted aBMD or BMC Z-scores in patients who were prepubertal at first examination; 10 of them were pubertal at second examination and two remained prepubertal (total $\mathrm{n}=14$ ). Lumbar spine aBMD Z-scores (mean difference [95\% CI], $-0.47[-0.92$ to -0.03$]$ ) and whole body less head BMC height- and BA-adjusted Z-scores ( -0.52 $[-1.01$ to -0.02$])$ decreased in patients who were pubertal at the beginning of the study and completed pubertal development during the follow-up (total $\mathrm{n}=17$ ). Whole body less head BMC height-adjusted Zscores decreased in patients who were postpubertal already at baseline (total $\mathrm{n}=14 ;-0.31[-0.61$ to 0.006$]$ ).

The BA-adjusted height $\mathrm{Z}$-score did not change significantly during the follow-up in the whole cohort (mean difference [ $95 \% \mathrm{CI}], 0.05$ [ -0.2 to 0.3$], P=.62$ ) or when analyzed separately for the patients treated with tumor necrosis factor$\alpha$ antibodies at the time of follow-up assessment $(\mathrm{n}=8,0.4$ [ -0.4 to 1.2$], P=.26$ ). Change in height SDS (median [range], 0 [-1.4 to 2.0$]$ ) correlated positively with change

Table III. Associations with low BA-adjusted lumbar spine aBMD $(<-1.0 \mathrm{Z}$-score $)$ with disease characteristics, pubertal development, anthropometrics, nutrition, and fracture history

\begin{tabular}{|c|c|c|c|}
\hline $\begin{array}{c}\text { Characteristic } \\
\text { n (\%) or median (range) }\end{array}$ & $\begin{array}{l}\text { Normal lumbar spine } \\
\text { aBMD }(n=28)\end{array}$ & $\begin{array}{l}\text { Low lumbar spine } \\
\text { aBMD }(n=17)\end{array}$ & $P$ value* \\
\hline Sex (boy/girl) & $13(46 \%) / 15(54 \%)$ & $9(53 \%) / 8(47 \%)$ & .67 \\
\hline Diagnosis (UC/CD) & $20(71 \%) / 8(29 \%)$ & $9(53 \%) / 8(47 \%)$ & .21 \\
\hline Age, y & $18.6(10.7-25.0)$ & $20.4(16.6-24.3)$ & .03 \\
\hline \multicolumn{4}{|l|}{ Disease characteristic } \\
\hline Duration of disease, $y$ & $7.9(6.0-19.8)$ & $9.1(6.8-15.1)$ & .35 \\
\hline IBD activity (inactive/mild-severe) & $21(75 \%) / 7(28 \%)$ & $11(65 \%) / 6(35 \%)$ & .28 \\
\hline Lifetime cumulative weight-adjusted prednisolone dose, $\mathrm{mg} / \mathrm{kg}, \mathrm{n}=44^{\dagger}$ & $132(2.7-1320)$ & $268(1.8-1050)$ & .03 \\
\hline Lifetime duration of GC treatment, days, $n=44^{\dagger}$ & $379(21-2507)$ & $650(21-4112)$ & .007 \\
\hline \multicolumn{4}{|l|}{ Pubertal development } \\
\hline $\begin{array}{l}\text { Pubertal status at dg } \\
\text { (pre-/pubertal/post-) }\end{array}$ & $17(61 \%) / 10(36 \%) / 1(4 \%)$ & $7(41 \%) / 9(53 \%) / 1(3 \%)$ & .50 \\
\hline $\begin{array}{l}\text { Pubertal status at visit } \\
\text { (pre-/pubertal/post-) }\end{array}$ & $2(7 \%) / 10(36 \%) / 16(57 \%)$ & $0 / 0 / 17(100 \%)$ & .007 \\
\hline \multicolumn{4}{|l|}{ Anthropometrics } \\
\hline Height SDS & $0.6(-1.3$ to 3.1$)$ & $-0.5(-2.8$ to 0.9$)$ & .002 \\
\hline LM Z-score & $-0.4(-2.5$ to 1.2$)$ & $-1.0(-2.6$ to 0.7$)$ & .05 \\
\hline FM Z-score & $-0.6(-4.5$ to 1.4$)$ & $-1.1(-2.7$ to 0.4$)$ & .15 \\
\hline Underweight/normal weight/overweight & $1(4 \%) / 18(64 \%) / 9(32 \%)$ & $4(24 \%) / 13(76 \%) / 0$ & .009 \\
\hline \multicolumn{4}{|l|}{ Vitamin D, fracture history, and smoking } \\
\hline Total vitamin D intake, $\mu \mathrm{g} / \mathrm{d}$ & $11.1(2.3-26.2)$ & $21.7(1.7-49.2)$ & .01 \\
\hline Serum 25(OH)D, nmol// $\mathrm{L}^{\dagger}$ & $59(37-120)$ & $75(26-107)$ & .38 \\
\hline Fracture history lifetime (no/any) & $20(71 \%) / 8(29 \%)$ & $11(65 \%) / 6(35 \%)$ & .64 \\
\hline VF present & $3(11 \%)$ & 0 & .27 \\
\hline
\end{tabular}

${ }^{*} P$ values from independent samples $t$ test, except those marked with $\dagger$ that are from Mann-Whitney $U$ test. 

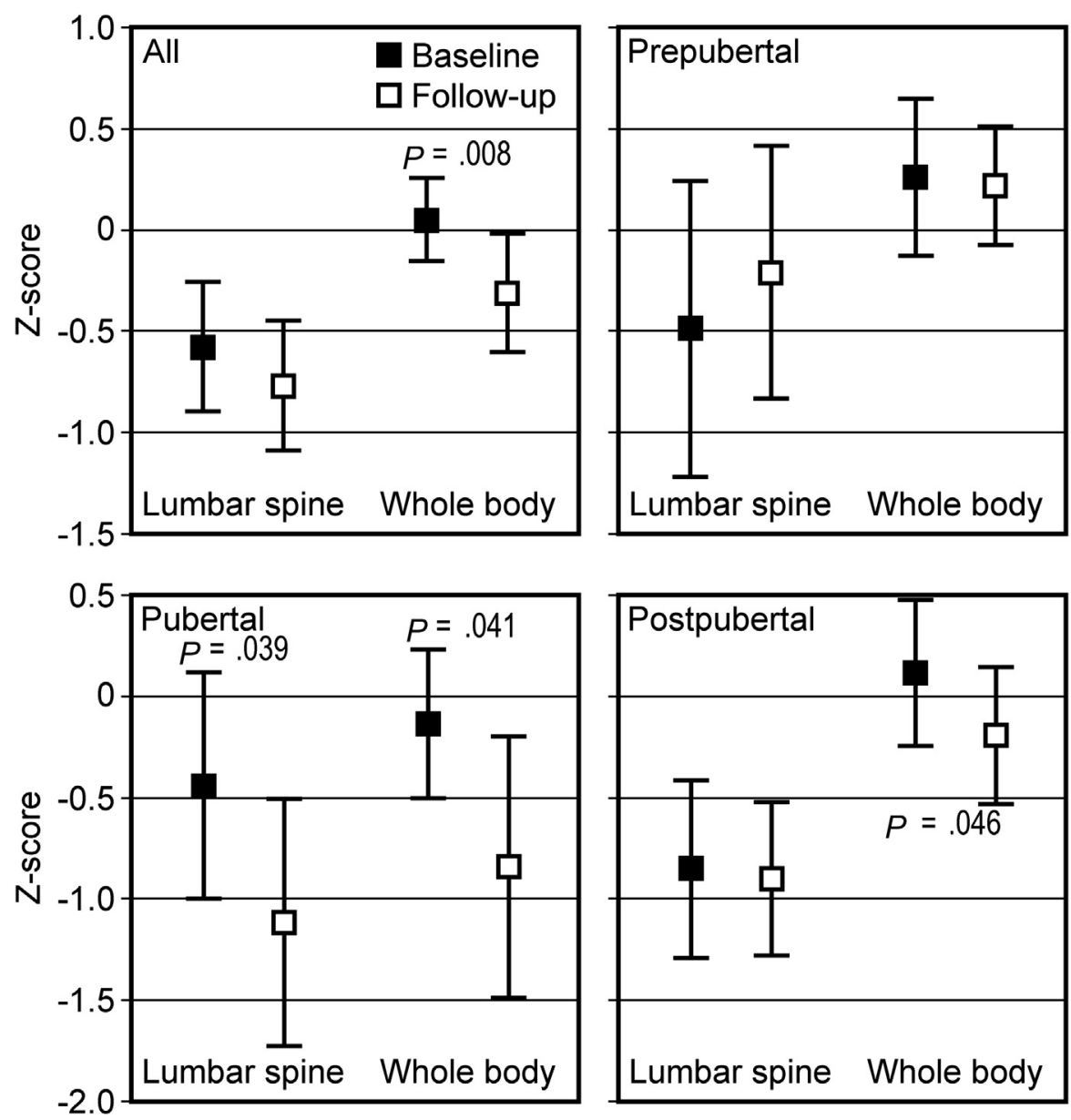

Figure. Bone mineral accrual in patients with pediatric-onset IBD. Values are given at baseline and at follow-up assessment for lumbar spine as BA-adjusted aBMD Z-scores and for whole body less head as height- and BA-adjusted BMC Z-scores. Values are given for the whole group and for subgroups determined by pubertal stage at baseline.

in lumbar spine aBMD Z-score in the whole cohort $(\tau=0.33$, $P=.002)$. Serum $25(\mathrm{OH}) \mathrm{D}$ levels and total vitamin $\mathrm{D}$ intake were greater at follow-up examination than at initial examination (Table IV; available at www.jpeds.com). Although only $47 \%$ of patients were initially examined during the summer, $85 \%$ of patients participated in the follow-up examination during the summer. The prevalence of vitamin $\mathrm{D}$ deficiency decreased from $30 \%$ to $7 \%$ during the follow-up. Patients with suboptimal serum $25(\mathrm{OH}) \mathrm{D}$ level $(<50 \mathrm{nmol} / \mathrm{L}, \mathrm{n}=11)$ did not differ significantly in lumbar spine aBMD (median [range]: $-0.8[-3.3$ to 0.5$]$ vs -0.6 [-2.9 to 2.9], $P=.51$ ) or whole body less head BMC BAand height-adjusted $\mathrm{Z}$-score from those with higher serum $25(\mathrm{OH}) \mathrm{D}$ levels $(-0.6[-2.9$ to 1.0$]$ vs -0.1 [ -2.5 to 2.0$]$, $P=.43)$.

\section{Fracture History and Vertebral Fractures}

Altogether, 8 peripheral fractures were reported in 7 patients during the follow-up. Two fractures resulted from a highenergy injury and 6 fractures from a low-energy injury. VFs were detected in three patients $(6 \%)$; they were $21-25$ years of age and all had UC with a disease duration ranging from 7.5 to 11.9 years. Single VF was found in 2 female patients and 7 VFs in a male patient; all fractures occurred in the thoracic region. One of the fractures was graded as mild anterior wedge deformity (2a), 2 as severe anterior wedge deformity (2b), and 6 as mild compression deformity (3a).

\section{Discussion}

IBD during childhood and adolescence puts normal growth and development of the skeleton at risk. During childhood and adolescence, bone mass increases to attain peak values by the end of the second or the beginning of the third decade; the greatest rate of mineral accumulation occurs during puberty. ${ }^{31}$ In our cohort, no improvement in bone mass accrual was observed during puberty. Moreover, lumbar spine aBMD Z-scores and whole body less head BMC height-and BA-adjusted Z-scores decreased significantly in patients who were pubertal at study onset and completed 
pubertal development during follow-up. Postpubertal patients showed significantly decreased aBMD, indicating suboptimal peak bone mass attainment during puberty. Previous studies on premenopausal women have suggested that juvenile-onset IBD leads to suboptimal peak bone mass. ${ }^{8,32}$ There are scarce previous studies on children and adolescents with IBD in which investigators explore the influence of puberty on BMD development, although follow-up studies have shown insufficient improvement in bone health after initiation of IBD treatment. ${ }^{5-7,9,10}$ No significant change was seen in BMD during a 2-year follow-up from diagnosis in 48 patients with $\mathrm{CD}$, of whom $72 \%$ were prepubertal or in early puberty at diagnosis. ${ }^{5}$ Greater improvements in trabecular vBMD Z-scores were demonstrated in subjects at Tanner stage I-II in comparison with those at Tanner stage III-V over 1-year follow-up by pQCT. ${ }^{9}$ However, a study following 102 children with IBD for 2.6 years by pQCT showed that improvements in height-corrected muscle cross-sectional area associated closely with bone measurements; the inclusion of pubertal stages had no effect on multiple linear regression models. ${ }^{10}$ Cross-sectional studies have found no association between pubertal maturation and lumbar spine bone mineral apparent density ${ }^{33}$ or whole body less head BMC. ${ }^{34}$ Studies exploring bone mineral accrual during puberty have used different classifications of pubertal stages, and subgroups have often had limited power to exclude negative findings. On the basis of these previous observations and our data, juvenile-onset IBD comprises a true risk for bone mass accrual during puberty. We have previously shown that in addition to patients with IBD, pediatric liver transplant recipients $^{35}$ and adolescents who had undergone allogeneic stem cell transplantation ${ }^{36}$ have inadequate bone mass accrual during puberty.

Delayed puberty is known to compromise peak bone mass permanently. ${ }^{37,38}$ Children and adolescents with IBD are at risk for delayed puberty and growth retardation because of malnutrition, GC therapy, and systemic inflammation. ${ }^{2,4}$ In our cohort, both increased age at menarche in girls and delayed BA in boys were observed as signs of pubertal delay at the follow-up visit. In addition to pubertal delay, growth retardation needs to be taken into account when exploring the impact of IBD on bone mass accrual. Regarding DXA results, there is a risk for underestimation of aBMD in children with reduced height. Although we adjusted whole body less head BMC Z-scores for both BA and height SDS, the values deteriorated significantly during the follow-up in the whole cohort. Height Z-scores at follow-up visit did not differ significantly from the expected heights calculated from parental heights, and no significant change in height $Z$-scores was observed during follow-up, in concordance with previous studies. ${ }^{39-42}$ In agreement with our results, improvements in height Z-scores have been correlated with higher bone mineral accrual rate. ${ }^{7,9}$

GC treatment in patients with IBD results in reduced bone formation by suppressing osteoblastogenesis, inhibiting chondrocyte proliferation and collagen synthesis, and by pro- moting bone resorption. ${ }^{4}$ In the follow-up assessment of our cohort, greater lifetime prednisolone dose was associated with low lumbar spine aBMD, reflecting possibly both more active disease and the side effects of GC treatment. The baseline data of the whole cohort of 80 patients indicated that cumulative weight-adjusted dose of prednisolone $\geq 150 \mathrm{mg} / \mathrm{kg}$ for the preceding 3 years was associated with increased risk for low BA-adjusted aBMD Z-score. ${ }^{12}$ In other studies, cumulative GC dose has been associated with reduced aBMD ${ }^{43-45}$ and correlated negatively with the change in lumbar spine BMD Z-scores. ${ }^{46}$ However, many studies have found no association between GC treatment and bone measurements or bone mineral accrual rate. ${ }^{5-7,10,34,47,48}$ Our strength concerning analyses on the effects of GC treatment is the careful collection of data, making it possible to calculate reliable lifetime cumulative weight-adjusted GC doses including all orally and parenterally administered GCs. In addition to cumulative GC dose reflecting disease activity, we estimated clinical disease activity indexes only at baseline and follow-up assessments. aBMD Z-scores did not improve at any measurement site over the median follow-up time of over 5 years, although the disease was clinically inactive in most of the patients at the follow-up visit. Clinically inactive state of disease does not necessarily correlate with mucosal healing that was not routinely evaluated during the study.

As possible consequences of compromised bone strength, we found subclinical VFs in $11 \%$ of the 80 patients with IBD at baseline by assessing the VFA images. ${ }^{12}$ By using both radiography and VFA-images, we found, at the follow-up visit, VFs in $6 \%$ of the patients. An epidemiologic study on fracture risk in pediatric patients with IBD has shown a strong trend towards increased VFs in pediatric patients with IBD. ${ }^{49}$ In contrary to previous reports on VFs in patients with $\mathrm{CD},{ }^{50,51}$ all VFs in our cohort were found in patients with UC.

Total intake of vitamin D increased during the follow-up and fewer patients were vitamin $\mathrm{D}$ deficient in comparison with the baseline assessment. However, one fourth of the patients still had 25(OH)D concentrations less than $50 \mathrm{nmol} / \mathrm{L}$, indicating a need for continuous monitoring of vitamin $\mathrm{D}$ status in patients with IBD. Patients with low lumbar spine aBMD had greater total vitamin D intake, but their serum $25(\mathrm{OH}) \mathrm{D}$ levels were not significantly greater, reflecting possibly impaired absorption of nutrients.

In conclusion, this longitudinal follow-up study on $47 \mathrm{pa}-$ tients with IBD over the pubertal years shows that IBD poses a significant threat for bone health during childhood and adolescence. The observed suboptimal peak bone mass attainment may have life-long consequences and predispose to symptomatic osteoporosis in early adulthood. More studies are needed to define mechanisms behind compromised bone mass accrual. Optimally, these studies should include larger cohorts, follow-up from disease onset to skeletal maturity, other methods in addition to DXA to assess skeletal characteristics, and interventions with vitamin D and weight-bearing exercise. Puberty may offer a window 


\section{of opportunity to improve BMD, although our study showed insufficient efforts during this critical period (eg, to ensure optimal vitamin D status).}

We thank research nurses Päivikki Rissanen and Nea Boman for their skillful assistance in this study.

Submitted for publication Oct 22, 2013; last revision received Dec 17, 2013 accepted Jan 29, 2014.

Reprint requests: Saila Laakso, MD, PhD, Children's Hospital, P. O. Box 281, Fl-00029 Helsinki University Central Hospital, Helsinki, Finland. E-mail: saila. laakso@helsinki.fi

\section{References}

1. Benchimol EI, Fortinsky KJ, Gozdyra P, Van den Heuvel M, Van Limbergen J, Griffiths AM. Epidemiology of pediatric inflammatory bowel disease: a systematic review of international trends. Inflamm Bowel Dis 2011;17:423-39.

2. Wong SC, Macrae VE, McGrogan P, Ahmed SF. The role of proinflammatory cytokines in inflammatory bowel disease growth retardation. J Pediatr Gastroenterol Nutr 2006;43:144-55.

3. Pappa H, Thayu M, Sylvester F, Leonard M, Zemel B, Gordon C. Skeletal health of children and adolescents with inflammatory bowel disease. J Pediatr Gastroenterol Nutr 2011;53:11-25.

4. Ezri J, Marques-Vidal P, Nydegger A. Impact of disease and treatments on growth and puberty of pediatric patients with inflammatory bowel disease. Digestion 2012;85:308-19.

5. Sylvester FA, Wyzga N, Hyams JS, Davis PM, Lerer M, Vance K, et al. Natural history of bone metabolism and bone mineral density in children with inflammatory bowel disease. Inflamm Bowel Dis 2007;13: 42-50.

6. Sylvester FA, Leopold S, Lincoln M, Hyams JS, Griffiths AM, Lerer T. A two-year longitudinal study of persistent lean tissue deficits in children with Crohn's disease. Clin Gastroenterol Hepatol 2009; 7:452-5.

7. Pappa HM, Saslowsky TM, Filip-Dhima R, DiFabio D, Lahsinoui HH, Akkad A, et al. Efficacy and harms of nasal calcitonin in improving bone density in young patients with inflammatory bowel disease: a randomized, placebo-controlled, double-blind trial. Am J Gastroenterol 2011;106:1527-43.

8. Mauro M, Armstrong D. Juvenile onset of Crohn's disease: a risk factor for reduced lumbar bone mass in premenopausal women. Bone 2007;40: 1290-3.

9. Dubner SE, Shults J, Baldassano RN, Zemel BS, Thayu M, Burnham JM, et al. Longitudinal assessment of bone density and structure in an incident cohort of children with Crohn's disease. Gastroenterology 2009; 136:123-30.

10. Werkstetter KJ, Pozza SB, Filipiak-Pittroff B, Schatz SB, Prell C, Bufler P, et al. Long-term development of bone geometry and muscle in pediatric inflammatory bowel disease. Am J Gastroenterol 2011;106:988-98.

11. Lennard-Jones JE. Classification of inflammatory bowel disease. Scand J Gastroenterol Suppl 1989;170:2-6. discussion 16-9.

12. Laakso S, Valta $H$, Verkasalo $M$, Toiviainen-Salo S, Viljakainen $H$, Mäkitie O. Impaired bone health in inflammatory bowel disease: a case-control study in 80 pediatric patients. Calcif Tissue Int 2012;91: 121-30.

13. Tanner JM. Growth at adolescence: With a general consideration of the effects of hereditary and environmental factors upon growth and maturation from birth to maturity. 2nd ed. Oxford: Blackwell; 1962. p. 325 .

14. Hyams JS, Ferry GD, Mandel FS, Gryboski JD, Kibort PM, Kirschner BS, et al. Development and validation of a pediatric Crohn's disease activity index. J Pediatr Gastroenterol Nutr 1991;12:439-47.

15. Harvey RF, Bradshaw JM. A simple index of Crohn's-disease activity Lancet 1980;1:514.
16. Turner D, Otley AR, Mack D, Hyams J, de Bruijne J, Uusoue K, et al. Development, validation, and evaluation of a pediatric ulcerative colitis activity index: a prospective multicenter study. Gastroenterology 2007; 133:423-32.

17. Walmsley RS, Ayres RC, Pounder RE, Allan RN. A simple clinical colitis activity index. Gut 1998;43:29-32.

18. Jowett SL, Seal CJ, Phillips E, Gregory W, Barton JR, Welfare MR. Defining relapse of ulcerative colitis using a symptom-based activity index. Scand J Gastroenterol 2003;38:164-71.

19. Best WR. Predicting the Crohn's disease activity index from the HarveyBradshaw Index. Inflamm Bowel Dis 2006;12:304-10.

20. Turner D, Seow CH, Greenberg GR, Griffiths AM, Silverberg MS, Steinhart AH. A systematic prospective comparison of noninvasive disease activity indices in ulcerative colitis. Clin Gastroenterol Hepatol 2009; 7:1081-8.

21. Sorva R, Lankinen S, Tolppanen EM, Perheentupa J. Variation of growth in height and weight of children. II. after infancy. Acta Paediatr Scand 1990;79:498-506.

22. Pere A. Comparison of two methods for transforming height and weight to normality. Ann Hum Biol 2000;27:35-45.

23. Saari A, Sankilampi U, Hannila ML, Kiviniemi V, Kesseli K, Dunkel L. New Finnish growth references for children and adolescents aged 0 to 20 years: length/height-for-age, weight-for-length/height, and body mass index-for-age. Ann Med 2011;43:235-48.

24. Physical status: the use and interpretation of anthropometry. Report of a WHO expert committee. World Health Organ Tech Rep Ser 1995;854:1452.

25. Sorva R, Tolppanen EM, Lankinen S, Perheentupa J. Growth evaluation: parent and child specific height standards. Arch Dis Child 1989;64:1483-

26. Pere A, Perheentupa J, Peter M, Voutilainen R. Follow up of growth and steroids in premature adrenarche. Eur J Pediatr 1995; 154:346-52.

27. Greulich WW, Pyle SI. Radiographic atlas of skeletal development of the hand and wrist. 2nd ed. Stanford (CA): Stanford University Press; 1959. p. $256 \mathrm{~s}$.

28. Zemel BS, Kalkwarf HJ, Gilsanz V, Lappe JM, Oberfield S, Shepherd JA, et al. Revised reference curves for bone mineral content and areal bone mineral density according to age and sex for black and non-black children: Results of the bone mineral density in childhood study. J Clin Endocrinol Metab 2011;96:3160-9.

29. Kelly TL, Wilson KE, Heymsfield SB. Dual energy X-ray absorptiometry body composition reference values from NHANES. PLoS One 2009;4: 7038.

30. Mäkitie O, Doria AS, Henriques F, Cole WG, Compeyrot S, Silverman E, et al. Radiographic vertebral morphology: a diagnostic tool in pediatric osteoporosis. J Pediatr 2005;146:395-401.

31. Boot AM, de Ridder MA, van der Sluis IM, van Slobbe I, Krenning EP, Keizer-Schrama SM. Peak bone mineral density, lean body mass and fractures. Bone 2010;46:336-41.

32. Bernstein CN, Leslie WD, Taback SP. Bone density in a populationbased cohort of premenopausal adult women with early onset inflammatory bowel disease. Am J Gastroenterol 2003;98:1094-100.

33. Paganelli M, Albanese C, Borrelli O, Civitelli F, Canitano N, Viola F, et al. Inflammation is the main determinant of low bone mineral density in pediatric inflammatory bowel disease. Inflamm Bowel Dis 2007;13: 416-23.

34. Burnham JM, Shults J, Semeao E, Foster B, Zemel BS, Stallings VA, et al. Whole body BMC in pediatric Crohn disease: Independent effects of altered growth, maturation, and body composition. J Bone Miner Res 2004;19:1961-8.

35. Valta H, Jalanko H, Holmberg C, Helenius I, Mäkitie O. Impaired bone health in adolescents after liver transplantation. Am J Transplant 2008;8: 150-7.

36. Taskinen M, Saarinen-Pihkala UM, Hovi L, Vettenranta K, Mäkitie O. Bone health in children and adolescents after allogeneic stem cell transplantation: high prevalence of vertebral compression fractures. Cancer 2007;110:442-51. 
37. Chevalley T, Bonjour JP, Ferrari S, Rizzoli R. Pubertal timing and body mass index gain from birth to maturity in relation with femoral neck BMD and distal tibia microstructure in healthy female subjects. Osteoporos Int 2011;22:2689-98.

38. Chevalley T, Bonjour JP, Ferrari S, Rizzoli R. Deleterious effect of late menarche on distal tibia microstructure in healthy 20-year-old and premenopausal middle-aged women. J Bone Miner Res 2009; 24:144-52.

39. Alemzadeh N, Rekers-Mombarg LT, Mearin ML, Wit JM, Lamers CB, van Hogezand RA. Adult height in patients with early onset of Crohn's disease. Gut 2002;51:26-9.

40. Pfefferkorn M, Burke G, Griffiths A, Markowitz J, Rosh J, Mack D, et al. Growth abnormalities persist in newly diagnosed children with Crohn disease despite current treatment paradigms. J Pediatr Gastroenterol Nutr 2009;48:168-74.

41. Lee JJ, Escher JC, Shuman MJ, Forbes PW, Delemarre LC, Harr BW, et al. Final adult height of children with inflammatory bowel disease is predicted by parental height and patient minimum height Z-score. Inflamm Bowel Dis 2010;16:1669-77.

42. Thayu M, Denson LA, Shults J, Zemel BS, Burnham JM, Baldassano RN, et al. Determinants of changes in linear growth and body composition in incident pediatric Crohn's disease. Gastroenterology 2010;139:430-8.

43. Gokhale R, Favus MJ, Karrison T, Sutton MM, Rich B, Kirschner BS. Bone mineral density assessment in children with inflammatory bowel disease. Gastroenterology 1998;114:902-11.
44. Semeao EJ, Jawad AF, Stouffer NO, Zemel BS, Piccoli DA, Stallings VA. Risk factors for low bone mineral density in children and young adults with Crohn's disease. J Pediatr 1999;135:593-600.

45. Lopes LH, Sdepanian VL, Szejnfeld VL, de Morais MB, FagundesNeto U. Risk factors for low bone mineral density in children and adolescents with inflammatory bowel disease. Dig Dis Sci 2008;53:2746-53.

46. Boot AM, Bouquet J, Krenning EP, de Münck Kezer-Schrama SM. Bone mineral density and nutritional status in children with chronic inflammatory bowel disease. Gut 1998;42:188-94.

47. Schmidt S, Mellstrom D, Norjavaara E, Sundh SV, Saalman R. Low bone mineral density in children and adolescents with inflammatory bowel disease: a population-based study from Western Sweden. Inflamm Bowel Dis 2009;15:1844-50.

48. Bechtold S, Alberer M, Arenz T, Putzker S, Filipiak-Pittroff B, Schwarz HP, et al. Reduced muscle mass and bone size in pediatric patients with inflammatory bowel disease. Inflamm Bowel Dis 2010;16:216-25.

49. Kappelman MD, Galanko JA, Porter CQ, Sandler RS. Risk of diagnosed fractures in children with inflammatory bowel diseases. Inflamm Bowel Dis 2011;17:1125-30.

50. Semeao EJ, Stallings VA, Peck SN, Piccoli DA. Vertebral compression fractures in pediatric patients with crohn's disease. Gastroenterology 1997;112:1710-3.

51. Klaus J, Armbrecht G, Steinkamp M, Brückel J, Rieber A, Adler G, et al. High prevalence of osteoporotic vertebral fractures in patients with Crohn's disease. Gut 2002;51:654-8. 
Table IV. Serum 25(OH)D, dietary intake of vitamin D and $\mathrm{Ca}$, and the frequency of vitamin $\mathrm{D}$ deficiency at baseline and follow-up assessments of young patients with IBD

\begin{tabular}{|c|c|c|c|}
\hline $\begin{array}{c}\text { Characteristic, } \\
\text { median (range) or } \mathbf{n}(\%)\end{array}$ & Baseline & Follow-up & $P$ value \\
\hline Serum 25(OH)D, nmol/L & $49(17-102)$ & $67(26-120)$ & .001 \\
\hline Season (summer) & $22(47 \%)$ & $40(85 \%)$ & $<.001$ \\
\hline $\begin{array}{l}\text { Dietary vitamin D intake, } \\
\mu \mathrm{g} / \text { day }^{\dagger}\end{array}$ & $3.9(0.9-11.5)$ & $4.7(1.1-24.5)$ & .16 \\
\hline $\begin{array}{l}\text { Vitamin D supplement } \\
\text { in use }\end{array}$ & $24(52 \%)$ & $29(63 \%)$ & .40 \\
\hline $\begin{array}{l}\text { Total vitamin D intake, } \\
\mu \mathrm{g} / \text { day }^{\dagger}\end{array}$ & $7.5(1.6-19.5)$ & $12.6(1.7-49.2)$ & .002 \\
\hline Dietary Ca intake, $\mu \mathrm{g} / \mathrm{day}^{\dagger}$ & $962(256-2820)$ & $1120(199-2830)$ & .27 \\
\hline Ca supplement in use & $20(43 \%)$ & $20(43 \%)$ & $>.99$ \\
\hline Total Ca intake, $\mu \mathrm{g} / \mathrm{day}^{\dagger}$ & $1380(678-2820)$ & $1420(287-3260)$ & .44 \\
\hline $\begin{array}{l}\text { Vitamin D deficiency }<37.5 \\
\qquad \mathrm{nmol} / \mathrm{L}^{\ddagger}\end{array}$ & $13(30 \%)$ & $3(7 \%)$ & .01 \\
\hline $\begin{array}{l}\text { Vitamin D insufficiency } \\
\quad<50 \mathrm{nmol} / \mathrm{L}^{\ddagger}\end{array}$ & $22(51 \%)$ & $11(26 \%)$ & .03 \\
\hline
\end{tabular}

${ }^{*} P$ values from paired-samples $t$ test and 2-sample test for equality of proportions with continuity correction.

†Total $\mathrm{n}=24$

$\ddagger$ Total $\mathrm{n}=43$. 